\title{
Gram-negative septicaemia during haemorrhage from an anastomotic ulcer
}

\author{
J. D. WARD ${ }^{1}$ \\ From the Medical Unit, The London Hospital
}

SYNOPSIS Gram-negative septicaemia (Klebsiella) occurred on two occasions in a patient bleeding from an anastomotic ulcer. It is postulated that the presence of this organism in the gut of such a patient provided the portal of entry for this infection.

The clinical picture of Gram-negative septicaemia and its causes are now well recognized and the following case illustrates an unusual cause.

\section{CASE REPORT}

A 73-year-old man, who had undergone posterior gastroenterostomy and vagotomy six years before, was admitted on account of a haematemesis. His general state was good $(\mathrm{Hb}=8.5 \mathrm{~g} / 100 \mathrm{ml})$, and he was transfused with whole blood. A barium meal suggested stomal ulceration. He remained well but there was evidence of continual bleeding and on the third day he rapidly became extremely ill with fever $\left(103^{\circ} \mathrm{F}\right)$, rigors, hypotension, and jaundice (bilirubin $8.3 \mathrm{mg} / 100 \mathrm{ml}$ - direct = $5.5 \mathrm{mg} / 100 \mathrm{ml}$; alkaline phosphatase $=28.6 \mathrm{~K}-\mathrm{A}$ units, SGOT $=78$ units). Blood culture produced a growth of an organism of the Klebsiella species and he was treated with intravenous cephaloridine ( $1.5 \mathrm{~g}$ in 24 hours).

Over four days there was marked improvement in his condition and he was apyrexial. On the fifth day he again collapsed at a time when haematemesis confirmed further bleeding and Klebsiella was again isolated from blood culture. Treatment with intravenous chloramphenicol was given ( $2 \mathrm{~g}$ in 24 hours for the first five days). There was steady improvement in his state and he left hospital three weeks after his second collapse.

\section{BACTERIOLOGY AND TREATMENT}

The Klebsiella organism grew readily on both occasions and the sensitivities of the organism were exactly the same on each occasion, that is, insensitive to ampicillin, fully sensitive to tetracycline, streptomycin, chloramphenicol, polymyxin, cephaloridine, and kanamycin.

Treatment with cephaloridine on the first occasion seemed to have produced clinical improvement but the patient had a relapse associated with another episode of bleeding. I would suggest that the dose of cephaloridine was inadequate for complete eradication of such a

${ }^{1}$ Present address: Department of Medicine, Guy's Hospital, London, S.E.1.

Received for publication 12 February 1969. severe infection and virtually useless in the presence of further invasion of the bloodstream with the second episode of bleeding. Chloramphenicol was substituted and was continued for two weeks at $1 \mathrm{~g} /$ day after the first five days.

Two months after the initial infection a Crosby capsule was passed into the afferent loop and under screening control was seen to pass well on towards the anastomosis. Samples of intestinal fluid were aspirated, but cultures were negative.

\section{DISCUSSION}

Reports of Gram-negative septicaemia appeared as early as 1924 (Felty and Keefer, 1924). More recently numerous reviews of large series have appeared (Hall and Gold, 1955; Spittel, Martin, and Nichols, 1956; Weil and Spink, 1958; McCabe and Jackson, 1962; Weil, Shubin, and Biddle, 1964; Waisbren and Arena, 1965).

The commonest factors causing or predisposing towards this condition lie in the genito-urinary tract, that is, following urethral instrumentation, and bladder, kidney, pelvic, and perineal surgery. Infection may occur during active pyelonephritis and following abdominal surgery, peritonitis, wound and skin infection, and in Gram-negative pneumonia. Septic abortion is a well recognized cause.

In this case no portal of entry could be demonstrated: urine cultures were sterile; catheterization was not performed; an intravening pyelogram was normal; there was no lung infection as a chest radiograph and screening of the diaphragms were normal; and there was no growth from transfusion bottles, giving sets, and cannulae. Gram-negative septicaemia undoubtedly occurred in close association with haemorrhage from an anastomotic ulcer, the possibility of haemorrhage from oesophageal varices being excluded by their absence on a subsequent barium swallow. 
Reports have appeared demonstrating the presence of Gram-negative organisms in the upper small gut of patients who have undergone gastric surgerygastrectomy and gastroenterostomy - and in small bowel disease (Shiner and Waters, 1963). E. coli is the organism most commonly found, but Proteus, Strep. faecalis, and Klebsiella also occur. The interest in this finding centres around the importance of these organisms in their relationship to bile salt metabolism and the resulting effects on absorption. In the studies of Tabaqchali and Booth (1966), Gram-negative organisms were isolated from loops of gut in postgastrectomy subjects, higher counts being obtained in those with longer 'stagnant' loops who showed evidence of malabsorption. However, organisms were also isolated from the guts of patients without malabsorption, and even in three patients with a Billroth I gastrectomy.

The presence of such organisms seems to be relevant to the problem of the source of infection in this patient, and it seems reasonable to suggest that in his case, while active haemorrhage was occurring in the region of the anastomosis, the Klebsiella organism gained access to the blood stream. Subsequent failure to culture the organism from the gut is probably related to the large amounts of antibiotic which the patient received. There was no evidence of malabsorption in this case.

Such a portal of entry does not seem to have been stressed in the past. In a number of reviews of the results and complications of gastric surgery (Hardy, 1964; Coe, McLaughlin, and Walker, 1964), such a problem is not mentioned, and in the series concerned with Gram-negative septicaemia itself, such a cause is irrelevant. However, there is some evidence to suggest that organisms may gain entry to the blood stream from the gut. In the series of $\mathrm{McCabe}$ and Jackson (1962), a small group of cases is mentioned under the heading 'ulcer, small bowel and cholan- gitis'. Haematemesis and gastrointestinal haemorrhage art features of Gram-negative septicaemia and this was present in $18 \%$ of the cases of Weil and Spink (1958), who excluded five cases in which haematemesis 'could have conceivably been a complication of gastric surgery'. Haltalin and Nelson (1965) report three children with $E$. coli septicaemia occurring in the course of shigellosis.

\section{CONCLUSION}

The purpose of this report is to draw attention to the possibility of bloodstream infection occurring directly from the gut during gastrointestinal haemorrhage in any patient who is likely to have Gramnegative organisms in the gut. Thus, in a postgastrectomy or malabsorption subject who is bleeding from the gut, it would be important to perform blood cultures if the patient's clinical state was not responding to blood transfusion, etc, in the expected manner.

I wish to thank Dr. R. R. Bomford for permission to publish this case and for his help in discussing the problem.

\section{REFERENCES}

Coe, J. D., McLaughlin, C. W., Jr. and Walker, E. (1964). Arch. Surg., 88, 888.

Felty, A. R., and Keefer, C. S. (1924). J. Amer. med. Ass., 82, 1430. Hall, W. H., and Gold, D. (1955). Arch. intern. Med., 96, 403 .

Haltalin, K. C., and Nelson, J. D. (1965). J. Amer. med. Ass., 192, 441. Hardy, J. D. (1964). Amer. J. Surg., 108, 699.

McCabe. W. R., and Jackson, G. G. (1962). Arch. intern. Med., 110,847 and 856 .

Shiner, M., Waters, T. D., and Gray, J. D. A. (1963). Gastroenterology, 45,625 .

Spittel, J. A., Jr., Martin, W. J., and Nichols, D. R. (1956). Ann. intern. Med., 44, 302.

Tabaqchali, S., and Booth, C. C. (1966), Lancet, 2, 12.

Waisbren, B. A., and Arena, J. (1965). Arch., intern. Med., 116, 336.

Weil, M. H., Shubin, H., and Biddle, M. (1964). Ann. intern. Med., $60,384$.

—_, and Spink, W. W. (1958). Arch. intern. Med., 101, 184. 